\title{
Floor Surfaces in Fireproof Buildings
}

\author{
Recommendations in Regard to Material and Methods of Construction \\ By Sanford E. Thompson
}

In fireproof construction, whether it be office building factory, or institution, the question of the type of floo surface to select and the method of construction to adopt is a most important one. The constant tread an shufting of feet cause a friction that it is difficult to withstand without serious wear.

From the construction standpoint, in a non-combustible structure a cement surface is in keeping with the rest of the building and is naturally the first considered. In many instances the cement concrete or granolithic fioor has proved extremely satisfactory, while in others, because of the use of improper constituents, inexpert construction, or of its selection for places to which it is not adapted, it has proved a disappointment As a matter of fact, no one type of fioor surface is adapted to all conditions, while for any type that is properly selected, the choosing of the material and the manner of the construction will govern to a large extent the durability of the surface.

It is the purpose of this paper to discuss briefiy the different kinds of fioor surfaces, and to compare their various qualities, their cost, and their adaptability to specific conditions. This is followed by a more detailed treatment of the methods of constructing the concrete or granolithic surface which have produced satisfactory results.

An engineer in consulting practice is called upon frequently not only to design and construct but to inve tigate defective construction and also to make special tests for the determination of the best methods to em ploy in a particular case. In this paper are embraced not only the results of experience in fioor construction and repairs, especially as they relate to granolithic surfaces, but also the conclusions derived from special test and investigations made in connection with services a consultant on the superstructure of the New Technology buildings in Cambridge.

The selection of the type of fioor is dependent on the character of the structure, the nature of the wear, and the architectural appearance. Every building must be considered by itself. Suggestions for the type of surface to select are covered in the following pages. $A \mathrm{~s}$ preliminary guide, the material suitable for differen onditions may be given as :

Basements: Granolithic finish with troweled surface made with approved materials and workmanship.

Factory Floors: Granolithic finish with troweled surface; hardwood.

Machine Shops: Granolithic finish with troweled surface; hardwood on substantial base.

Ground Floors for Heavy Manufacturing: Wood block; granolithic

Warehouses: Granolithic with troweled surface asphalt composition; hardwood.

Offices: Hardwood ; linoleum on concrete; magnesium composition.

Corridors and Halls for institutions and office build ings: Terrazzo; granolithic finish with ground surface Entrance Pavilions: Terrazzo; mosaic; tile; natura stone.

Class Rooms, Lecture Rooms, and Drawing Rooms: Linoleum on concrete; granolithic with ground surface hardwood; magnesium composition.

Laboratories: Granolithic with troweled surface; magnesium composition; tile; hardwood.

Lavatories: Terrazzo; granolithic finish with groun surface; tile.

The above selections are given in the order in which choice might be made for the average building or room of each class.

CHARACTERISTICS OF FLOOR SURFACES.

Granolithic Troweled. As ordinarily laid in build ings, granolithic or concrete surfaces are subject to dusting and under heavy traffic, such as trucking, ar liable to serious wear. On the other hand, experience with first-class construction and tests of actual fioor shows that it is possible, by proper selection of the aggregates and expert workmanship, to reduce the dustin to an insignificant amount and to produce a surface hard enough to stand even severe wear.

For factory fioors, notwithstanding many cases of inferior construction, the use of granolithic is largely increasing. It is becoming recognized that the durability of granolithic is in a very large measure dependent upon the sand or other aggregates used in th construction and the methods of laying it

The chief objection to concrete or granolithic surface - From a paper read before the American Society of Me chanical Engineers. for offices, drafting rooms, class rooms, and certain aboratories, is that it is dull in appearance, hard on the feet for men standing all day, tends to break tools dropped upon it, and is not adapted to attaching seats and other furniture readily, especially where they have to be shifted occasionally. In certain colleges, however concrete surfaces are used widely and highly recommended. At Bowdoin and at the University of Wisconsin it is considered satisfactory for all purposes. At the University of Missouri the newer buildings are all being built with granolithic surfaces. In some colleges granolithic is being satisfactorily used for corridors. Most of the colleges favor granolithic for chemical, mining, and mechanical laboratories. The Leland Stanford, Jr., University states that in the mechanical and engineering laboratories the men complain of hardness and coldness, requiring wood platforms in many places. In this university, however, granolithic has been used in the chemical laboratories for fifteen years with ex cellent satisfaction. It should be noted, further, that in the mechanical and engineering laboratories the floor rests directly on the ground, while in the chemical laboratory there is a warm room or basement underneath. The life of a well laid granolithic surface under foot traffic is practically permanent.

Granolithic with Ground Surface. Experimental sur faces, together with laboratory tests made as a check, show that a pleasing surface, approaching terrazzo in appearance and fully as durable under foot traffic, can be obtained by placing granolithic with scarcely any trowelling, and then grinding the surface just enough to expose the grains of sand and stone. The grains which show are finer than in terrazzo and darker colored. The appearance, however, is pleasing. Removal of the scum takes away the monotony of the plain gray cement surface, since this is relieved by the various colors of the sand and stone. A glossy effect can be produced if desired by the grinding which permits of easy cleaning and gives a surface suitable even for a lavatory at much less cost than tile or terrazzo. Still further to give variety to the appearance, tile can be placed in patterns or as a border.

The University of Missouri, which refers to the dust from granolithic floors, believes that this difficulty trowelling. ecifications giving the method of laying the concrete granolithic and grinding it are presented at the end of this paper. From observations of the time
required for grinding the surfaces and allowing amply for delays, the extra cost for grinding is estimated not to exceed 3 cents per square foot of surface area.

Linoleum. The hardness and noise characteristic of granolithic finish are overcome by covering the surface with Battleship linoleum. In the few colleges where this has been adopted they are very enthusiastic over the results. In other places, such as offices, the same type of construction meets with a great deal of favor At the University of Chicago cork carpets are used, which answer a similar purpose.

Linoleum is laid on a concrete surface, which need not be brought to a fine finish, and therefore can be completed at the time the base concrete is laid and at a low cost. Any marring of the surface or sudden rains will not affect its use for the linoleum finish.

The linoleum should be stuck firmly to the granolithic surface and preferably a cove base should be run around the room and sills provided at entrances so that the surface of the granolithic will be flush. In this way the edges are prevented from fraying. The life of firstclass quality Battleship linoleum, if edges are not frayed, is probably from fifteen to thirty years, depend ing upon the amount of travel. These ages are estimated from records of linoleum now in use.

Linoleum, after allowing for the better finish required on the concrete, costs substantially the same as a single floor of birch or maple, but it is noiseless, more uniform in appearance, and requires less labor for maintenance in good condition. Its superiority to wood is indicate by the fact that wood fioors are frequently covered with linoleum.

Hardwood Floors. Floors of maple, birch, becch, oak, or long leafed Southern pine are used most largely for offices, class rooms, or lecture rooms, and in many of the older colleges for laboratories and halls. A wood surface, however, is not usually considered entirely satisfactory either in general appearance or in wearing qualities. If one passes from a corridor with a granolithic, terrazzo, or tile floor, into a room or auditorium lithic, terrazzo, or tile floor, into a room or auditorium ority and cheapness. There is just as much danger of poor materials and workmanship with wood as with other kinds of fioors. Unless the greatest care is taken in selection of materials and workmanship, they are liable to shrink or swell and sometimes to squeak under foot. If at all hollow underneath, they are more noisy than a concrete surface. The floors of the New Grand Central office buildings are an example of this.

For corridors, wood is being largely superseded by gianolithic, terrazzo, or tile. For laboratories other materials are being substituted for wood in most of the newer structures, although wood is occasionally preferred, especially for physical laboratories and for laboratories where men stand for long periods. The linoleum on concrete will overcome practically all the objections that are made to wood floors, with a cost substantially the same.

There are various methods of laying hardwood floors. For class rooms a single thickness of maple or birch nailed to sleepers with cinder concrete between should be satisfactory. Another type of construction is to use patented metal screeds embedded in the base concrete, and nail the floor boards to splines in the screeds. For rooms subjected to heavy traffic, 2 -inch or $2 \frac{1}{2}$-inch plank may be placed underneath the hardwood floor. of all the different materials, oak is the most expensive and the finest in appearance at the beginning, but under heavy traffic is more liable to splinter than the finer grained woods. Georgia pine, if of best quality, makes a durable floor, and is preferable to the finer grained woods in wet places, as it does not swell and warp so badly. It is less durable, however, and therefore not recommended for the greatest permanence in rooms such as class and lecture rooms. Maple, birch, and beech all make good floor material. These are usually laid in strips $7 / 8$ inch thick by $21 / 4$ inches wide. The quality varies largely, ranging in cost from $\$ 32$ to $\$ 75$ per 1,000

Terrazzo. Terrazzo is made by spreading upon the base concrete a mixture of neat cement and marble chips and grinding the surface to a depth sufficient to cut into stones and expose them on their largest diameters. Marble. sometimes white and sometimes colored. is used, and since no sand is employed the particles may be of fairly uniform size. The joints between the particles being of neat cement are hard and even more durable than the pieces of the marble themselves. Large pieces of marble, from $3 / 4$ inch to 1 inch in diameter, give a more distinctive floor but cost more than a floor of the smaller stones, from $1 / 8$ inch to $1 / 2$ inch in diameter, because the large stones require much more grinding to get down to the large diameters of the particles. There is more tendency to crack than in a good granolithic properly bonded to the base, but if laid with the best workmanship, this cracking is reduced to a minimum. 'Jerrazzo is largely used, especially in the newer office buildings and in institutions, for corridors and halls. It also is satisfactory for lavatorios, although more expensive than granolithic. It appears from our investigation that for both of these uses concrete with a ground surface can be substituted at less cost and with satisfactory results. In certain cases objectionwhich applies also to any hard material like granolithic or tile--is raised to terrazzo because of the noise, and even corridors are covered with linoleum or similar material.

Marble Mosaic. Mosaic consists of small squares of marble laid on the cement bed, something like terrazzo. Surfaces are ground enough to make all pieces true and level. The price of mosaic is too high to be considered for large areas and in many cases the pieces of marble pull out from the surface. Mosaic is suitable in certain cases for an ornamental border which is not subject to

Magnesium Composition. When laid with great care, composition is a satisfactory and durable material. Floors six or eight years old have been examined and show satisfactory wear. The work must be done by a responsible firm with a suitable guarantee bond, because even with the greatest care the work is occasionally imperfect. The imperfections, however, are apt to show within the first year of service. Composition is more resilient than granolithic, so that there are less complaints of hardness. It is nearly, but not quite, as noisy. Furniture can be screwed directly to the composition. Composition has not yet been used to a great extent in colleges. The fioors of Cooper Union in New York city results have been satisfactory. It is suitable for cer- 
tain school laboratories, such as physical and biological. Asphalt Composition. Asphalt composition is suitable for certain places where no heavy tools or machines are liable to press into the soft surface. It is resilient an easy to walk and stand upon. The color is not pleasing, being a dead black. In a few colleges it has been used satisfactorily for chemical laboratories. At Har vard, for example, asphalt mastic on top of wood has been in satisfactory use for many years. Johns Hopbeen in satisfactory use for many years. Johns Hop-
kins considered this material for their new chemical laboratories but abandoned it because of its viscous properties, substituting granolithic finish, which has proved satisfactory.

Tiles. Tiles of various colors is an excellent materia for corridors, lavatories, and even for laboratories, but is too expensive to use except where required for architectural treatment. There are various types and qualities of tile, ranging from quarry tile to cork and rubbe tile. All of them, however, are expensive.

Wood Block. Wood block may be suitable in certai cases for a basement fioor having severe usage. In the University of Cincinnati wood block is used in the mechanical and electrical testing laboratories and appears to be satisfactory.

TESTS AND INVESTIGATIONS OF GRANOLITHIC FLOORS.

The material used most largely for floor surfaces in factory construction and also to a considerable extent on other structures is what is termed a granolithic surface. This, as generally understood, is a layer of mortar or concrete from $1 / 2$ inch to 2 inches thick, usually about 1 inch on top of the concrete slab and bonded to it. Although granolithic or concrete floors are so widely employed, neither the materials nor the methods of construction are standardized and scarcely two contractors or engineers adopt the same methods. Moreover the materials available in a given locality largely affect the choice.

In order to compare the materials, that is, the aggre gates, available for new Technology, and to determine the best proportions and methods of laying these materials, a series of sample surface were laid at the factor: of the Simplex Wire and Cable Company, in Cambridge Also, comparative tests were made with similar materials in other locations. A few preliminary laborator tests were carried through, and certain tests to dete mine the best method of bonding a new granolithic surface to a hardened concrete base. As a result of these experiments, the following recommendations are made for the granolithic finish of fioors for which this material is to be used. The conclusions apply also to structures in general.

Materials. The various aggregates used in the test include three kinds of sand mixed as mortars in different proportions, and combinations of these sand with samples of different granites and traps. One or two sections were also laid with a patented compound.

Careful examination and comparisons of the various sections of slab with reference to hardness and appearance led to the selection of Plum Island sand, which should be specified to have not more than 10 per cent of its grains pass a sieve having 50 meshes to the linea inch, and not more than 2 per cent pass a sieve havin 100 meshes to the linear inch; and crushed granite of a size which has passed the $3 / 4$-inch screen in a crusher plant and been caught on the $\frac{3}{16}$-inch screen.

As a result of this selection, a slab of considerable area was laid at a later date at the Simplex factor with the selected materials and proportions, and in position where it would receive rather hard usage. The Simplex Company have recently advised us that the consider this slab the best piece of granolithic that has been laid in the factory.

Proportions. Different proportions of the material were employed in the various sample sections, each of which was about 2 feet wide by 3 feet long. The principal proportions tested were $1: 2$, with sand alone $1: 1 \frac{1}{2}$ with sand alone; $1: 1: 11 / 4$ with sand and finc crushed stone; $1: 1: 1 \frac{112}{2}$ with the same materials, an $1: 3 / 4: 11 / 4$. As a result the proportions selected as best are one part cement to $3 / 4$

Method of Laying Granolithic. Instead of using a Method of Laying Granolithic. Instead of using a
soft, flowing mixture, the best results were obtained by soft, flowing mixture, the best results were obtained by
using a fairly stiff mixture, stiff enough to be rammed in place by a square-faced rammer, which would bring the mortar readily to the surface. In this way the surface skin is thinner, there is less liability to dust, and the body of the concrete, which is of a better quality than with a wetter mix, is reached with comparatively little wear, so that the dusting does not continue.

Treatment of Surfaces. Dusting is temporarily overcome by paint, but this is always unsatisfactory because it wears off under ordinary travel, and if the concrete is not of the hest quality it then hegins to dust.

Grinding Surfaces of Granolithic. Objections to granolithic finish are dusting of the surface, the dead gray color, and the liability of local defects. Experi- ments show that these can be overcome by grinding the surfaces with a carborundum machine. This method
was followed on a section of slab at the Simplex Wire and Cable Company.

The general plan adopted is similar to that used with terrazzo finish. Instead, however, of grinding off a considerable thickness and thus entailing a large expense per square foot, only a very thin layer is taken off so as to show the grains of sand and the pieces of coarser aggregate. With this treatment, the surface is of a varied texture, and shows the various colored grains, and permits of different effects by using aggre gates of different colors. While the effect is not so conspicuous as the terrazzo, the surface is of a quieter tone, and should be satisfactory for ordinary corridors and halls. The grinding renders the surface more glossy and denser, so that it is possible to use this treatment with good results in a lavatory or other places where frequent washing and cleaning is required. - produce a more ornamental effect, borders or patterns of tile may be placed in the concrete.

Bond of Granolithic to Base Concrete. A perfect bond between the granolithic and the base concrete is the base concrete has reached its set. Surfaces thus laid are liable to injury from the workmen who have to go upon them before they have hardened thoroughly, and occasionally an unexpected shower will roughen the surface in such a way that it is very difficult to repair. To determine the best method of bonding, one which would give thorough assurance of perfect adhesion ests were made and then tried out in the field on a arge concrete building.

Laboratory tests were made on bonding new mortar to an old concrete surface, using various methods of treatment of surface, including acid treatment, rough-
ening, and no surface treatment whatever. As bonding material, neat cement was used in different conditions of plasticity, also certain patented compounds. As a result of these tests and experience in the field, a rough ened surface of the old concrete, with neat cement paste brushed in, is recommended as an effective method to produce a positive bond. It was shown in the tests that with a proper neat cement bond on a roughened surface the break under tension was frequently through concrete rather than at the joint

Preparing Concrete Base for other Surface Materials. If some other material than granolithic is used for the condition concrete must be left in a most materials, such as hardwood finish, composition asphalt and similar treatments, the surface of the base must be brought more nearly level than where granolithic is used. This can be accomplished by very careful screeding of the surface, trowelling of rough places, and filling holes made by footprints before the concrete has hardened.

For linoleum, a real granolithic is not required, but the surface must be level and true. This should be accomplished by spreading a thin layer of mortar before the base concrete is set, but this need not be of the very best quality of granolithic unless with the object of using portions of the floor without linoleum. This thickness of the mortar may be $1 / 2$ inch to $3 / 4$ inch. This should be troweled at the proper periods, but with less care than for a granolithic that is to be used as wearing surface. Some form of cove base around the walls is advantageous to use with the linoleum.

\section{High-Speed Engines*}

For the last four or five years we have been producing in some of our factories on the other side highspeed engines which will run successfully in touring automobiles without any more trouble than the ordinary slow-speed engines. In fact, five years ago the company I was connected with were in a position to give a three years' guarantee with their automobiles, the engines of years' guarantee with their automobiles, the engines of
which ran at a maximum speed of about 2,500 to 2,600 which ran at a maximum speed of about 2,500 to 2,600
revolutions per minute. Within the last two or three revolutions per minute. Within the last two or three
years we have been producing engines which have been developing maximum power at 2,400 revolutions per minute, and these have accelerated to 2,800 revolutions per minute on the slightest down grade. These particular automobiles have not only been successful in the British Isles, but have been highly satisfactory and successful in our colonies, such as Australia, New Zealand, etc., where the roads are, I think, pretty much on a land, etc., where the roads are, I think, pretty much on a
par with American roads. In fact, just before leaving par with American roads. In fact, just before leaving who was in Australia looking into the matter. His report, as well as the agent's report on the behavior of automobiles there, not only of our own production but of highspeed-engined cars produced by other firms, was to the effect that they were entirely satisfactory.

I am stating these points because in discussing them with some of the engineers here I have found that"quite * Paper read by D. McCall White and published in the S. A.E.
Bulletin. an erroneous idea seems to exist regarding the durability of the high-speed engine fitted into a moderately light chassis. The chassis which these engines are called upon to pull are not light, being in most cases of about the same weight as some of the modern chassis here. These chassis stand up not only in Britain but also in the colonies. A horse-power represents 33,000 footpounds of work, whether it is developed in Britain or in America, and if the required horse-power can be obtained with a smaller engine, greater economy will result. As an example of what has been done, I havedesigned a fourcylinder engine of 2 11/16-inch bore and 5-inch stroke, which developed 36 brake-horse-power at 2,600 revolutions per minute. It was fitted to a 110-inch wheelbase chassis weighing 1,680 pounds. This automobile could pull on top gear at 10 miles per hour on a very decent grade, in practically the same manner as a six-cylinder automobile with an engine of $31 / 4$-inch bore and 5 -inch stroke. The wheelbase of the six was 126 inches and the chassis weight about 2,632 pounds. Both chassis carried a load of driver and one passenger, plus a weight of 896 pounds. The small automobile was only three or four miles an hour slower than the large one. Obviously, the small engine was more efficient and developed a much higher mean effective pressure than the larger engine.
Undoubtedly, the most efficient valve mechanism which the combustion chamber is more perfect and presents less cooling surface to a given volume of gas than any other arrangement. This arrangement has, however, an inclination to become noisy, as, due to the inertia of the valve gear, which is undoubtedly greater than with any other type and naturally requires correspondingly stronger springs to prevent valve chatter, the rocker especially if the engine is of the efficient high-speed type. If the engine is not of this type, there is no necessity for overhead valves.

One can get highly satisfactory results with the exhaust valve in the orthodox position and the inlet overhead. With this arrangement about 15 to 25 per cent more charge can enter the cylinders for a given size of valve than with the L-head type of motor. The power of motor depends largely upon its volumetric efficiency.

I have been astonished to find how many of the engineers on this side still favor the T-head type of motor. I have found this arrangement to be the least efficient on record, it being necessary in order to get even moderate efficiency to use a two-spark magneto with spark plugs on either side of the combustion chamber. I have proved this contention more than once. It has also been proven by the fact that two spark plugs make very little difference in the L-head typ

For ordinary sizes of racing motors it is, in my opinion, For ordinary sizes of racing motors it is, in my opinion,
entirely unnecessary to fit multiple valves unless it is entirely unnecessary to fit multiple valves unless it is
desired to run the engine somewhere about 5,000 revolutions per minute, or unless the bore of the cylinder be so large and the stroke so long that two ordinary valves would be entirely too large. Regarding the design of valves and valve gear generally, I would say that lately I took part in some experiments with an engine running at 4,000 revolutions per minute and developing power at that speed, the valves being side-by-side in the conventional L-headed manner. The results were certainly astonishing.

I have been using in my own automobile an engine which developed full power at 3,000 revolutions per
minute, the bore being $31 / 8$ inch and the stroke $51 / 8$ inch. The wheelbase of the chassis was about 126 inches and the weight about $1,900^{\circ}$ pounds. This automobile could touch about 70 miles per hour in touring trim, with open torpedo body but no wind screen. The acceleration was good from about 7 miles per hour an hour on top gear.

\section{Railway Rail Production and Failures}

Bulletin No. 170 of the American Railway Enginee ing Association dealt with statistics of rail failures furnished to the American Railway Association by various, but not all, of the railways in the United States and Canada. These show that during the year ended October 31st, 1913, there were 63,472 tons rolled on the Bessemer process and 703,557 tons by the open-hearth process. In 1909, when about the same total tonnage was rolled, the figures were 432,155 for Bessemer an 461,261 for open-hearth. The failures in 1911-the years 1912 and 1913 are too recent to afford any conclusion as to failures-were 37.4 per 10,000 tons of open-hearth rails and 94.2 per 10,000 tons of Bessemer rails, which taking the open-hearth failures as 100 per cent, means 252 per cent for the Bessemer. In 1909 the open-hearth rails had 109 failures per 10,000 tons and the Besseme 212.4, which, again taking the open-hearth failures as 100 per cent, gives 195 per cent for the Bessemer. The percentages in favor of open-hearth rails have increased year by year, which, the report says, suggests the thought that there were faulty practices in the early rollings of open-hearth rails since improved upon. 